\title{
UNA NUEVA LIS: EL NACIMIENTO DE LUIS JOSÉ JAVIER DE BORBÓN, DUQUE DE BORGOÑA, Y SU REPERCUSIÓN EN LA MONARQUÍA ESPAÑOLA (1751)
}

\author{
A New Lys: The Birth of Louis Joseph Xavier of Bourbon, Duke of \\ Burgundy and its Impact in the Spanish Monarchy (1751)
}

Sergio Belmonte Hernández

Universidad Complutense de Madrid. España sbelmont@ucm.es | http://orcid.org/0000-0001-7655-1771

Fecha de recepción: 18/02/2021

Fecha de aceptación: 10/11/2021

Acceso anticipado: 25/11/2021

Resumen: El nacimiento de Luis José Javier de Borbón, duque de Borgoña, varón primogénito de los delfines de Francia, en 1751, aseguró la sucesión a la corona francesa. Se realizaron múltiples fiestas para celebrar el natalicio como era tradición. Estas no solo se circunscribieron al espacio francés, sino que se trasladaron a otras cortes europeas. Estudiamos aquí el caso de España y su especial significación, debido a la delicada situación política entre las dos potencias borbónicas, a través de los festejos dados por el embajador y las poderosas colonias de comerciantes franceses y cuyo objetivo era la recuperación de la amistad española por parte de Francia.

Palabras clave: duque de Borgoña; fiesta; Luis XV; conde de Vaulgrenant; pacto de familia; colonia mercantil.

Abstract: The birth of Louis Joseph Xavier de Bourbon, duke of Burgundy, male firstborn of the dauphins of France, in 1751, assured the succession to the French crown. Many parties were carried out to celebrate it according to the tradition. The parties were celebrated not only in France but also in other European courts. We study here the case of Spain and it relevant signification, in due the delicate 
political situation among both Bourbon powers, through the celebrations given by the ambassador and the powerful French colonies whose objective was to recover the Spanish friendship by France. colony.

Keywords: duke of Burgundy; party; Louis XV; count of Vaulgrenant; Family Compact; trade

Sumario: 1. Introducción; 2. La nueva lis borbónica en Europa y España; 3. La situación política entre Francia y España en 1751; 4. La embajada de Vaulgrenant; 5. Las celebraciones por el nacimiento del duque de Borgoña en Madrid; 6. Las celebraciones en el resto de la península; 6.1. Cádiz; 6.1.1. Descripción de las celebraciones; 6.2. Tenerife; 6.2.1. Descripción de las celebraciones; 6.2.2. El panegírico; 6.3. Murcia; 6.3.1. Descripción de las celebraciónes; 6.3.2. El panegírico; 7. Los comerciantes y la identidad francesa; 8. Conclusiones; 9. Referencias bibliográficas; 9.1. Impresos; 9.2. Estudios

\section{INTRODUCCIÓN}

El 13 de septiembre de 1751 nació en Versalles Luis José Javier de Borbón, hijo de Luis Fernando de Borbón y María Josefa de Sajonia, delfines de Francia. Como primogénito de los herederos recibió el título de duque de Borgoña. Su nacimiento fue muy esperado por la corte y en especial por su abuelo, el rey Luis XV. El monarca francés había perdido a una nieta, fruto del primer matrimonio del delfín con la infanta española María Teresa Rafaela, y aunque el nacimiento de otra, Maria Ceferina, hija del delfín y de la nueva delfina causó regocijo en la corte ${ }^{1}$, sin embargo, se seguía esperando un varón. Los temores de Luis XV ante la falta de otro heredero no eran infundados. El rey francés había accedido al trono de manera fortuita, las trágicas muertes sucesivas de su abuelo, el gran delfín, de su padre Luis, duque de Borgoña y de sus dos hermanos mayores lo elevaron al primer puesto en la línea de sucesión al trono francés a la muerte de Luis XIV (Chaline, 2009). Por otro lado, el mismo rey había estado a punto de morir en su juventud, situación que provocó una crisis sucesoria de la que Felipe $V$ de España intentó sacar partido al postularse como candidato a la corona francesa (Kamen, 2000, pp. 195-198). La sucesión era algo muy frágil.

Luis XV recibió la noticia del nacimiento de su nieto mientras se encontraba en el Petit Trianon. Uno de los guardias de corps llegó exhausto al pequeño palacete localizado en los jardines de Versalles gritando, «iUn duque de Borgoña!» (Stryiensky,

${ }^{1}$ El nacimiento de la pequeña princesa desplegó el aparato de propaganda de la monarquía como se demuestra del lienzo pintado por Natoire. En la obra vemos a Juno como matrona, al lado de su pavo real. La diosa envía a un ángel que sostiene en brazos a la pequeña y se lo ofrece a Francia, representada con manto de lises y corona real. Al fondo aparece el Louvre, un arco del Triunfo y la Diosa Minerva con casco. Tamaña alegoría denotaba que su nacimiento causó alegría general. La pintura se encuentra en el Musée Nationale de Chateaux de Versailles et de Trianon con número de inventario: MV 5975; INV 6860; MR 2202. 
1902, p. 127). Como era tradicional en todas las monarquías europeas se prepararon celebraciones para festejar el parto de la delfina. En todas las ciudades del reino francés se levantaron decoraciones efímeras, se hicieron luminarias y se tiraron fuegos de artificio $^{2}$, se confeccionaron multitud de litografías que representaban el momento del natalicio, una de ellas se incluyó en el almanaque real de $1752^{3}$, se escribieron panegíricos en honor al recién nacido (Soret, 1751), incluso el gran maestro de la música francesa, Rameau, compuso una obra musical ${ }^{5}$. En todas ellas se alababan las virtudes de la casa de Borbón, las cuales serían heredadas por esta nueva flor de lis.

Al día siguiente del nacimiento, los reyes, el delfín y Mesdames, así como el resto de la corte asistieron a un Te Deum en la capilla de palacio y se tiraron fuegos artificiales en el pueblo de Versalles que terminaron en desastre con el incendio de una de las caballerizas y la muerte de un guardia de corps (Delorme, 2020, p. 51).

Luis XV comunicó su deseo de realizar un Te Deum en Notre Dame de París para dar gracias por el nacimiento de su nieto y para ello informó al arzobispo de París. El prelado ordenó a todas las parroquias de la diócesis parisina que celebraran por todo lo alto el acontecimiento ${ }^{6}$. El 19 de septiembre, el rey, el delfín y los príncipes de sangre salieron de Versalles en dirección a París. El poco ahínco con el que los parisinos acogieron la noticia y la falta de muchedumbres vitoreando a la familia real impactó al soberano. La propaganda monárquica intentó aparentar una situación de normalidad y describió el acontecimiento como un regocijo general para el pueblo parisino, pidiendo el rey que su carroza se moviera más lenta de lo normal para que el público pudiese contemplarle mejor ${ }^{7}$. Sin embargo, la situación era diametralmente opuesta. El rey decidió condonar la deuda de 4 millones de libras francesas que la ciudad de París debía de las tallas, y donó el dinero de los festejos por el nacimiento del duque de Borgoña como dote para casar a jóvenes doncellas (Petitfils, 2014, p. 467). El monarca esperaba con esto levantar los ánimos, pues su semblante durante la celebración de la ceremonia denotaba preocupación

2 Por citar alguna de las muchas, por ejemplo: (1751). Représentation du feu d'artifice tiré le 3 Octobre 1751 sur la rivière d'Ill... à l'occasion de la naissance de Monseigneur le Duc de Bourgogne. S.I; S.L. BNF: FRBNF41925337.

${ }^{3}$ Almanach pour l'année bissextil M. DCC L II. París: chez Charpentier, rue S.t Jacques au Coq. BNF: FRBNF41507546.

${ }^{4}$ Se cita el compuesto por Monsieur Soret, pero se escribieron muchos otros.

${ }^{5}$ Rameau, J. P. (1751). Achante et Céphise. París: chez l'auteur, rue de Richelieu, vis-à-vis la bibliothèque du Roi: la Veuve Boivin, marchande, rue Saint Honoré, à la Régle d'Or : M. Leclerc, marchand, rue du Roule, à la Croix d'or. BNF: FRBNF41416888.

${ }^{6}$ (1751). Mandement... qui ordonne que le Te Deum sera chanté... en actions de grâces de l'heureux accouchement de madame la dauphine et de la naissance d'un duc de Bourgogne. París: Imprenta C. Simon. BNF: FRBNF33791097.

7 Mercure de France, Tomo LXI, julio-diciembre 1751, p. 172. 
(Stryiensky, 1902, p. 131). No surtió efecto la estratega paternalista del monarca, pues a la llegada a París del delfín y la delfina para un nuevo Te Deum el 26 de septiembre, fueron recibidos bajo los gritos de la muchedumbre que reclamaba pan y lanzaba insultos contra la favorita del monarca, Madame de Pompadour (Petitfils, 2014 , p. 509), considerada como la causante del hambre e instigadora de todas las guerras en las que Francia había estado inmersa.

Puede interpretarse el nacimiento del duque de Borgoña como un acontecimiento común, habitual y sin novedad en el marco de las monarquías europeas, sin embargo, la cantidad de impresos publicados como panegíricos, obras musicales, descripciones de fiestas y decoraciones efímeras y grabados a lo largo y ancho del territorio francés denotaban que el príncipe nacido era ansiado y que su nacimiento trascendía más allá de convertirse en nuevo miembro de la familia real ${ }^{8}$. El nuevo príncipe venía a cumplir uno de los discursos característicos de la monarquía ilustrada como era la felicidad pública.

\section{LA NUEVA LIS BORBÓNICA EN EUROPA Y ESPAÑA}

El nacimiento del duque de Borgoña fue también celebrado fuera de las fronteras francesas. Los embajadores de Luis XV en las diferentes cortes europeas, Géno$\mathrm{va}^{9}$, Viena ${ }^{10}$, Sajonia ${ }^{11}$, Venecia ${ }^{12}$, hicieron magníficas fiestas para festejar el acontecimiento, a los que se unieron los miembros del comercio francés, siempre dispuestos a expresar sus sentimientos de afinidad a Francia. No quedaron exentas de estas celebraciones las cortes de familia, aquellas donde reinaban miembros de la Casa de Borbón. Tanto el ducado de Parma, lugar donde reinaba la hija mayor del rey francés, Luisa Isabel, junto a su marido el infante Felipe ${ }^{13}$, como el reino de Nápoles y Sicilia donde reinaba Carlos de Borbón ${ }^{14}$, primo del monarca francés, celebraron

${ }^{8}$ A pesar de ser común las celebraciones por el nacimiento de príncipes, la falta de estos, y especialmente de varones, durante períodos de tiempo prolongados generaba una celebración mayor. En España destaca el caso del nacimiento de los infantes gemelos en 1783, hijos de los príncipes de Asturias, futuros Carlos IV y María Luisa de Parma. El acontecimiento se celebró prácticamente en todas las ciudades de la corona y al contrario que en anteriores ocasiones, todas las ciudades confeccionaron panegíricos y descripciones de los festejos. A la alegría por nuevos herederos se sumó la victoria de España junto a Francia en la guerra de independencia norteamericana (Igual Castelló, 2019).

${ }^{9}$ Gaceta de Madrid, 48, pp. 379-381.

${ }_{10}$ Gaceta de Madrid, 52, pp. 409-410.

${ }^{11}$ Gaceta de Madrid, 43, pp. 342.

12 Gaceta de Madrid, 45, pp. 356-357.

${ }^{13}$ Gaceta de Madrid, 44, p. 348.

${ }^{14}$ Gaceta de Madrid, 45, p. 356. 
el acontecimiento como merecía al tratarse del nacimiento de un nuevo miembro de la misma dinastía. La noticia también llegó a la corte española donde el conde de Vaulgrenant, embajador francés, informó a los entonces monarcas, Fernando VI, primo de Luis XV, y Bárbara de Braganza. El rey español dispuso de forma solemne la celebración de un Te Deum y de luminarias ${ }^{15}$. No obstante, a pesar de la cordialidad, las relaciones entre ambos soberanos no atravesaban su mejor momento. Necesidad inexcusable del monarca francés era recuperar la simpatía de su primo español, y por ello el nacimiento del duque de Borgoña fue instrumentalizado con miras políticas a conseguir este objetivo.

\section{LA SITUACIÓN POLÍTICA ENTRE FRANCIA Y ESPAÑA EN 1751}

Las relaciones diplomáticas entre Francia y España a la altura de 1751 pasaban por momentos de crisis, si no de ruptura. Las buenas relaciones entre ambas potencias durante el contexto de la guerra de Sucesión, en la que Luis XIV apoyó a su nieto para conservar el trono de España (Bernardo de Ares, 2011, pp. 39-47) y los posteriores acuerdos signados con Francia, los Pactos de Familia, se acabaron rompiendo. Aliadas ambas monarquías en 1733 y 1743 en el marco de las guerras de Sucesión de Polonia y Austria, los Borbones consiguieron recuperar Nápoles y Sicilia y después el ducado de Parma. Parecía que los intereses dinásticos se habían supeditado a los intereses de carácter «nacional», pues la recuperación de Italia pasaba por las ambiciones de Felipe $\mathrm{V}$ de reconstruir de forma completa la monarquía dinástica que había heredado de los Habsburgo y entronizar en la península itálica a sus hijos, mientras que el interés «nacional» pasaba por el desarrollo del territorio peninsular español y de la defensa y explotación de las Indias. La unión de Francia y España para la búsqueda de una política dinástica, sin embargo, se materializó solo en las campañas italianas y no llegó más lejos. El interés dinástico de la casa de Borbón española era esencialmente europeo y mediterráneo y no atlántico, lugar este último que se estaba convirtiendo en el centro del mundo. En 1735, el cardenal Fleury, ministro de Luis XV, firmó unos preliminares de paz sin el consentimiento de España que tenían como fin poner término a la guerra de Sucesión de Polonia. El ministro del rey francés ambicionaba recuperar la política pacifista que había caracterizado su mandato. Las presiones de Versalles obligaron a Felipe $\mathrm{V}$ a firmar el acuerdo que se materializó en la paz de Viena de 1738. El acuerdo permitió la obtención de Nápoles y Sicilia para el infante don Carlos, pero a cambio tuvo que renunciar a Parma y Piacenza. En 1745, el marqués de Argenson, ministro de exteriores del monarca francés, volvía a actuar a espaldas de España y concertaba unos preliminares que culminaron en la paz de Aix la Chapelle en 1748 que pusieron fin a

\footnotetext{
15 Gaceta de Madrid, 38, p. 304.
} 
la guerra de Sucesión Austríaca. Francia había violado, por segunda vez, uno de los puntos del pacto de Familia al comenzar negociaciones con las otras potencias sin el común acuerdo de España, cosa que irritó a Felipe V (Baudrillart, 1890-1901, t. 5, pp. 372-373, nota 13). El acuerdo consiguió los ducados de Parma y Piacenza para el infante don Felipe. Sin embargo, Felipe $V$ fallecía el 9 de julio de 1746 y el nuevo monarca Fernando VI tenía unas miras políticas diferentes a las de su padre.

La alianza dinástica de los Pactos de Familia se había roto por la traición de Francia al concertar paces sin tener en cuenta a la corte de Madrid. No obstante, no es de extrañar la actitud de la corona francesa, pues la política dinástica en Europa al lado de España no le había reportado ningún beneficio. Había sido la corte española, que entronizó a dos infantes, la verdadera beneficiada. Francia, a pesar de la invasión de los Países Bajos austríacos y de un posible intercambio de estos por el ducado de Parma (Sage, 1903, pp. 686-701), se vio obligada a devolver Flandes a la emperatriz María Teresa, y si podía considerar algún beneficio material era que la hija mayor de Luis XV, Luisa Isabel, fuera duquesa de Parma. Pero la actuación de la corona francesa fue temeraria pues Fernando VI estaba molesto por no haberse tratado en Aquisgrán otros asuntos más allá de los puramente dinásticos como era el tema de Gibraltar o el del fin de la concesión del asiento de negros a Gran Bretaña. La subida de Carvajal a la secretaría de Estado en diciembre de 1746 marcaría un giro radical de la política exterior española dejándose en suspensión el Pacto de Familia. El nuevo secretario de estado aborrecía de la tradicional alianza con Francia y puso en marcha lo que se ha denominado como una política de neutralidad (López Cordón, 2000, pp. 191-193). Carvajal pensaba llevar una política cortés y de buenas palabras con todas las cortes europeas, pero no comprometerse con ninguna incluida Francia (Delgado Barroso, 2001, pp. 57-89; Ozanam, 2006).

\section{LA EMBAJADA DE VAULGRENANT}

La pérdida de la alianza española fue un revés para la corte francesa que por su imprudencia se vio privada de la ayuda militar española, fuerza necesaria en caso de una más que previsible guerra con Inglaterra. Los efectos empezaron a notarse. Por ejemplo, los embajadores franceses, considerados como embajadores de familia, perdieron su fácil acceso al rey católico (Ozanam, 2000, pp. 21-22). La nueva situación en la corte española fue advertida al conde de Vaulgrenant, nombrado embajador en la corte de Madrid. El conde, que había desempeñado labores diplomáticas en Cerdeña y Sajonia, ya había sido embajador en España anteriormente, entre 1734-1738. Durante su primera misión en la corte madrileña logró de Felipe V su adhesión a los preliminares que llevarían a la paz de Viena de 1738 , a pesar de que el monarca español nunca estuvo de acuerdo con estos. Es por esta razón y por su experiencia en la corte madrileña por lo que Luis XV cree que es la mejor opción 
para intentar recobrar el favor de España (Morel Fatio, 1899, p. 280). En las instrucciones dadas al diplomático se reflejaban las intenciones de Versalles:

L'union entre les deux couronnes est un des points fondamentaux sur lesquels Sa Majeste [Luis XV] a établí la base de son gouverment politique. (Morel Fatio, 1899, p. 286).

Sin embargo, se aconsejaba al embajador prudencia a la hora de actuar para evitar agravar la situación en España. Debía atraerse a Carvajal, y sobre todo a Ensenada, a quien Versalles consideraba pro-francés, así como intentar evitar que los ministros españoles predispusieran a los monarcas católicos contra él mismo. Vaulgrenant también llevaba otra instrucción importante. Debía defender a capa y espada los intereses de los comerciantes franceses en la Monarquía española.

\section{LAS CELEBRACIONES POR EL NACIMIENTO DEL DUQUE DE BORGOÑA EN MADRID}

En mitad de su embajada, Vaulgrenant recibió la noticia del embarazo de la delfina. El embajador había sido preguntado ya un año antes por el ministro de exteriores Puyzieulx sobre la mejor forma de celebrar un natalicio por parte de la embajada francesa en Madrid. El conde respondió que lo tradicional eran tres intensos días de fiestas, incluyendo un Te Deum, refrescos, bailes y cenas. El ministro respondió en nombre de Luis $X V$ que fiestas tan pomposas hubieran sido adecuadas en el caso de que siguiera viva la antigua delfina, hija de Felipe $V$ y primera esposa del delfín, pero que las circunstancias habían cambiado (Ozanam, 2000, pp. 231232). Sin duda, el rey francés se refería a que las antiguas relaciones del pacto de Familia se habían roto y que ahora era consecuente actuar de una forma más discreta. Sin embargo, Vaulgrenant no comprendió esta negativa de su monarca, pues como reflejaban las instrucciones dadas desde Versalles, su principal labor era recuperar la amistad española. Se quejó a Puyzieulx de que Fernando VI «seguía siendo un miembro de la Casa de Borbón y que nada mediocre podría ser admitido». A pesar de que el rey español hubiera iniciado una política exterior prescindiendo de Francia se le debía tener en cuenta y se le debía vincular a las fiestas por el natalicio del nuevo duque de Borgoña. Luis XV a través del ministro de exteriores terminó de forma tajante con las ambiciones del embajador y le asignó 18000 libras para las fiestas, presupuesto que Vaulgrenant consideraba del todo insuficiente (Ozanam, p. 232) El recién nacido resultó ser una niña, María Ceferina. Al no ser un varón los festejos fueron suspendidos.

Sin embargo, la delfina volvió a quedarse embarazada, esta vez del duque de Borgoña, y Puyzieulx intentó dar satisfacción a Vaulgrenant en esta ocasión, pero no 
tuvo éxito. El embajador sabedor de las anteriores intenciones del rey de recortar el presupuesto intentó rebajar sus pretensiones e informó de que suprimiendo algunos de los eventos como el Te Deum o la comida dada a ilustres hombres de la corte se podían ahorrar unas 1400 libras. No obstante, a pesar de haber reducido el gasto, el presupuesto que daba el conde, 22400 libras, excedía la cifra anteriormente otorgada. Conocida la noticia del alumbramiento del pequeño duque, y sustituido Puyzieulx por el marqués de Saint Contest al frente del ministerio de exteriores, se le concedían a Vaulgrenant 50000 libras para realizar los festejos. El nuevo ministro instó a realizar la fiesta con toda rapidez lo que supliría la falta de magnificencia de una celebración que había de durar tres días (Ozanam, p. 232). A pesar de ser su presupuesto mucho mayor que el anterior, el embajador francés insistió en que era insuficiente, pero la corte francesa no admitió más quejas y el conde se dispuso a hacer lo mejor que pudiera con el dinero asignado. Avispado, el francés concentró todo el esplendor irradiado de Versalles en Madrid en solo veinticuatro horas. Se incluyeron fuegos de artificio, refresco, luminarias, cena y baile. Como decía el embajador a Saint Contest, «reduciendo los tres días que son de etiqueta a uno solo intentaré hacer tan vistoso y completo como sea posible» (Ozanam, p. 232).

El elemento formal más destacable de la fiesta es el arco de triunfo efímero que se erigió. Este se describe en una relación transcrita por Yves Bottineau (1986, pp. 435-440). El arco presentaba en el primer cuerpo una cascada de agua y encima de ella se encontraban dos ríos, el Tajo y el Sena, que representaban a Francia y España. En la parte más alta del edificio, sobre un pedestal coronado en el ático, se veía la cifra del rey de Francia (XV) unida a la del rey de España (VI), sostenidas por la amistad y los amores. Se eligió a François Carlier para la construcción del arco efímero. Ninguno de estos mensajes, ni siquiera la elección del arquitecto, eran inocentes. Decantarse por Carlier se debía a que era francés, su padre había sido discípulo de Robert de Cotte, y había estudiado arquitectura en París ${ }^{16}$, lo cual lo hacía estar familiarizado con las creaciones francesas. El arco en honor al nacimiento del duque de Borgoña guarda relación con la arquitectura efímera levantada en el río Sena en 1704 titulada "Le Trimphe de la Seine et du Tage sur les autres flueves de L'Europe», con motivo del nacimiento del duque de Bretaña. La coincidencia no podía ser mayor. La obra también se erigía en honor del nacimiento del primogénito varón del delfín. Se trataba del hermano mayor de Luis XV, que murió con solo un año de edad y nunca llegó a reinar. Este nacimiento fue festejado por todo lo alto también en Madrid. La decoración efímera mencionada formaba parte de un conjunto mayor de celebraciones. La fiesta parisina tuvo un marcado carácter político, pues se desarrolló en plena guerra de Sucesión. La unión de los ríos Sena y Tajo,

${ }^{16}$ Sancho Gaspar, J. L. Francisco Antonio Carlier. Diccionario Biográfico de la Real Academia de la Historia. Recuperado el 07 de febrero de 2021 de https://dbe.rah.es/biografias/17382/ francisco-antonio-carlier 
Francia y España, vencían al resto de los ríos, Danubio y Támesis, El Imperio y Gran Bretaña, o sea los enemigos de Felipe V (De la Gorce, 2006, p. 49-51). La obra era un reflejo por excelencia de la llamada unión de coronas. De la construcción se decía:

La naissance de Monseigneur le duc de Bretagne, donnant à la Maison royale une longue suite de descendents d'aine en aine, assure en meme temps à l'Espagne le bonheur qu'elle a d'etre commandée par un Roy que le ciel a fait naitre pour lui rendre son ancienne splendeur, est un Nouveau gage de son union éternelle avec la France : union qui respecter leur empire par toutes les Nations. Cést ce que l'on a voulu exprimer par le Triomphe de la Seine et du Tage sur les autres Fleuves de l'Europe ${ }^{17}$.

Carlier debía conocer estas arquitecturas efímeras por fuerza y tuvo que tenerlas en cuenta para la creación del arco.

Quedaba claro que el gran artífice y mente promotora había sido el embajador Vaulgrenant. La elección del tema de los ríos, usada con anterioridad en otra fiesta de carácter dinástico, y la unión de las cifras de Fernando VI y Luis XV bajo la amistad y el amor tenían la misión de recordar al rey de España que el pacto de Familia era la única alianza posible para la corte de Madrid. Es de destacar que a pesar de las advertencias del monarca galo de que las circunstancias con España habían cambiado y de que en las instrucciones dadas al embajador desde Versalles se le recomendaba prudencia, como antes hemos mencionado, el diplomático usó para sus propósitos del lenguaje alegórico de la fiesta y emitió un mensaje que toda persona bien formada, cualquier miembro de la corte y otros embajadores podía entender a la perfección. Sin duda, Vaulgrenant contradijo las intenciones del rey francés, lo que podía poner en serios apuros la imagen de Francia en la corte española y en especial ante los reyes. Sin embargo, la fiesta fue un triunfo. A pesar de los continuos recortes presupuestarios se dijo que jamás hubo fiestas tan completas en Madrid, hasta los reyes mostraron su satisfacción (Ozanam, 2000, p. 233). El conde había conseguido un éxito rotundo.

\section{LAS CELEBRACIONES EN EL RESTO DE LA PENÍNSULA}

Las fiestas por las celebraciones del nacimiento del duque de Borgoña no se limitaron a las del embajador en Madrid. La colonia francesa de comerciantes en España, la más numerosa, también se sumó a las celebraciones. La instauración en

17 (1704). Le triomphe de la Seine et du Tage, Sur les autres fleuves de l'Europe, affermi par la naissance de Monseigneur le duc de Bretagne. París: Imprenta de Jean L'Esclapart, p. 4. BNF: FRBNF36298031. 
España de la Casa francesa de los Borbones en 1700 fue una oportunidad para el comercio francés, que vio la posibilidad de beneficiarse de los numerosos recursos de la Monarquía Hispánica. La concesión del asiento de negros a la compañía de Guinea y la completa libertad de flotas de comercio francesas para recalar en puertos de la América hispana pusieron las riquezas indianas en manos del comercio galo, motivo que fue decisivo para el estallido de la guerra de Sucesión (Albareda, 2010, pp. 64-72). A pesar de la cesión del asiento de negros a Gran Bretaña tras la firma de la paz de Utrecht, los franceses se impusieron como el grupo mercantil extranjero más grande y activo en España (Bennassar, 2004, p. 22).

Escenarios de festejos por el natalicio fueron la ciudad de Cádiz, colonia francesa por excelencia, Tenerife, cuyo consulado era bastante polémico, y Murcia, epicentro de todo el comercio de levante. Según la lista de extranjeros confeccionada en el censo de 1791 existían en España unos 26000 extranjeros de los cuales el 52 \% eran franceses (Salas Ausens, 1990, p. 161). Las zonas geográficas meridionales y Madrid eran las que concentraban mayor porcentaje de franceses. Las preferencias venían marcadas por las grandes ciudades del sur, los puertos y la capital. El resto de la península, sobre todo el interior, eran de menor importancia comercial para los franceses (Salas Ausens, 2009, pp. 153-251). No es de extrañar, por tanto, que fueran en estas zonas donde se celebrara el nacimiento del duque de Borgoña.

\subsection{Cádiz}

La colonia francesa en Cádiz era la mayor y más importante de la península. La ciudad se había convertido en objeto de deseo por parte de los grupos mercantiles extranjeros desde el traslado de la Casa de la Contratación desde Sevilla en 1717 (Bustos Rodríguez, 1995, pp. 202-238). Era el único puerto autorizado para acceder al comercio con las Indias españolas. La población no cesó de crecer y en 1750, un año antes de las celebraciones por el nacimiento del duque de Borgoña, la ciudad alcanzó entre los 50 000-55 000 habitantes ${ }^{18}$. El número de franceses en Cádiz en 1751 rondaría los 1000, pues en 1713 había 912 y en 1773 su número era de 1459 (García-Baquero González y Collado Villalta, 1990, p. 178), habiendo aumentado en 547 en un período de 60 años. Es de reseñar que la actividad comercial con Indias solo era posible si se era natural de los reinos de España. Algunos franceses que llevaban tiempo residiendo en la península solicitaban y se acogían al estatuto de "naturalizados», con lo cual se consideraban súbditos del rey de España y se les otorgaba la licencia por parte del consejo de Indias para comerciar con América (Bartolomei, 2017, pp. 253-302). Los que se acogían a esta medida perdieron los privilegios como súbditos franceses otorgados por el consulado francés, como se

18 Manuel Bustos Rodríguez (2016) señala para 1750 unos 50500 habitantes mientras que José María Molina Martínez (2004, p. 95) arroja la cifra de 54100. 
desprendía de la pragmática de Luis XV de 21 de diciembre de 1716. No obstante, esto no quiere decir que olvidaran sus raíces francesas pues algunos se declaraban como franceses o como españoles cuando convenía a sus intereses (Ozanam, 1968, pp. 260-264). Diversas medidas fueron puestas en marcha para distinguir a unos de otros como las listas mandadas confeccionar por la corona en 1764 y 1791, cuyo objetivo era discernir entre franceses transeúntes, aquellos bajo la autoridad del consulado, y franceses avecindados, aquellos bajo la autoridad de la corona española. La corona francesa por medio del consulado y este a través de las asambleas de diputados impedían la participación de los avecindados, ya que dejaban de ser vasallos de Francia (Le Gouic, 2013, p. 106). Eran, por lo tanto, los transeúntes, o sea súbditos de Luis XV, los que organizan las fiestas por el duque de Borgoña.

\subsubsection{Descripción de las celebraciones}

Los consulados franceses dependían del ministerio de marina francés. El titular, marqués de Rouillé, envió carta al cónsul de Cádiz, Pierre Desvanes, avisando del parto de la delfina. Se reunió unos días después la asamblea en el consulado para tratar los festejos que se deberían hacer. Se acordaron tres días de celebraciones con Te Deum, este realizado en la capilla de San Luis del convento de San Francisco, refrescos, cenas, luminarias, y fuegos artificiales. Se construyó en la plaza de San Francisco un templo dedicado al Genio de Francia. La decoración con medallones aludía a temas como la esperanza depositada en el recién nacido y sus presuntas cualidades y a la perennidad de la estirpe de los Borbones (Ozanam, 2000, p. 235). Al templo se le añadió una estatua de Luis XV, vestido a la romana, realizada en mármol. La inscripción que acompañaba a la obra presentaba al monarca galo como amantísimo padre de la patria. En la plaza de San Antonio, en la residencia del cónsul se dio un opíparo banquete a la nobleza local y autoridades y se les dio un lugar exclusivo en el teatrillo creado ex profeso en el mismo lugar para contemplar los fuegos artificiales. La misma plaza se llenó de gentío que fue a observar las iluminaciones del templo del Genio de Francia. (Ozanam, p. 235). Algo resaltaba de estos festejos, que hemos resumido, y su simbolismo, en comparación con aquellos realizados en Madrid. Mientras en la capital se aludía de forma clara a los lazos dinásticos y a la unión natural entre ambas casas de los Borbones, las fiestas en Cádiz carecieron de este discurso y simplemente consagraron la fiesta al duque de Borgoña, a Luis XV y a su "patria», Francia, dando de esta manera prueba de la lealtad aquellos franceses, lejos de su lugar de origen, al monarca cristianísimo.

\subsection{Tenerife}

El consulado francés en Canarias también festejó el natalicio del duque de Borgoña. La existencia de esta institución en Tenerife estaba más determinada a ser un 
elemento de prestigio para la corona francesa que una verdadera próspera colonia mercantil. Juan Antonio Porlier, que desempeñó el consulado entre 1713 y 1748, decía que «en estas islas, aunque hay varios franceses, solo dos hacen algún comercio, y aún muy mediocre» (Ozanam, 2002, p. 2174). Los ingresos que podían obtenerse provenían de la exportación de vino de malvasía, que apenas aportaba beneficios. Las islas interesaban en tanto en cuanto recalaban allí embarcaciones de la compañía francesa de las Indias Orientales, pero realmente todo el comercio estaba en manos de Gran Bretaña (Ozanam, p. 2175). Porlier se vio casi arruinado para poder mantener el consulado, a pesar de que, tras múltiples quejas, el gobierno le había asignado el salario que pedía. El cónsul pudo realizar algunas actividades de mecenazgo como la financiación de la construcción de una capilla en honor a San Luis en la iglesia de San Francisco de Tenerife (Ozanam, p. 2178). Muerto Esteban Porlier y tras el breve ínterin de su hijo, la corona francesa nombró a François CasaIon como nuevo cónsul. Este fue sucedido por su sobrino Enrique, quien organizó la celebración del natalicio del duque de Borgoña. El cónsul encargó un sermón panegírico que fue impreso en Tenerife y que se desmenuza a continuación.

\subsubsection{Descripción de las celebraciones}

El lugar elegido para el Te Deum fue la iglesia-convento de San Francisco. La elección no era casual debido a que se trata del templo que cobijaba la capilla de San Luis financiada por Porlier. El lugar por lo tanto estaba bajo la protección del consulado. El 22 de abril de 1752 se realizan las primeras celebraciones adornando el templo, prendiendo la pira en la que se sustentaba la eucaristía. A las dos la tarde empezó la música y por la noche se encendieron luminarias y se tiraron fuegos artificiales en la plaza del convento. A estos festejos acudió el gentío. A la mañana siguiente, día 23 de abril, se celebró el Te Deum y se entonó el panegírico Fray Blas de Medina, perteneciente a la congregación de franciscanos del templo religioso. Al acto acudieron el cónsul, la colonia de comerciantes franceses, el capitán general, y numerosos nobles y gente del clero y de la milicia. Los buques mercantes franceses dispararon salvas de cañón. Después se celebró una misa mayor y salió la hostia consagrada en procesión. Por la tarde se dio un banquete a la nobleza y autoridades tinerfeñas por parte de los miembros del consulado y se repartió limosna para 2000 pobres, y enfrente de las casas del consulado se dispararon fuegos artificiales hasta las diez de la noche, y continuaron después la música con sonatas y conciertos (Medina, 1752, s.f).

\subsubsection{El panegírico}

El sermón panegírico tinerfeño se encuadra prácticamente dentro del discurso puramente religioso con vagas alusiones políticas. La obra se confecciona con pleno 
conocimiento de los sucesos en Francia en relación al nacimiento del duque de Borgoña relatados al inicio del artículo. Se cuenta la historia del guardia de corps suizo que anunció el nacimiento a Luis XV en el Trianon y al que se compara con un ángel haciendo analogía con el nacimiento de Cristo. También se cita la decisión del rey francés de utilizar el dinero para los festejos en París en dotar a 600 doncellas para casarlas (Medina, 1752, p. 7). Se presenta la grandeza de la estirpe del recién nacido, entroncando a la dinastía Borbón con Jesé. Este recurso fue muy utilizado por panegiristas ya desde el renacimiento y usado ampliamente por los Habsburgo (Mínguez y Rodríguez Moya, 2020, pp. 325-340). El pequeño retoño era descrito como una nueva flor de lis, al igual que en Francia. De la raíz, que era su abuelo Luis $\mathrm{XV}$, y del tronco, que era su padre, el delfín, nacía lo más bello que era él, la flor de lis. El natalicio debía ser motivo de festejo en todas partes del mundo:

Gusto semejante no es para un reino solamente, no para una sola corte, no para una casa, no para una familia, sino para todos los pueblos de la tierra. (Medina, 1752, p. 2).

No hay en la obra más que vagas referencias o alusiones a la pretendida alianza de Francia o España tales como

Este duque [...] para todos es [...] consuelo perpetuo de su monarquía [...] alegría inexplicable de España. (Medina, 1752, p. 2).

O se hacía referencia a que los festejos en Santa Cruz se hacían «no solo en los corazones interessados de la gloria de su nación [Francia], sino también en los vecinos, y amigos a quien capta la atención y llama novedad tan feliz» (Blas Medina, 1752, p. 2).

No obstante, estas frases no tenían el sentido político instrumentalizado que el embajador Vaulgrenant sí dio a las fiestas en Madrid. En este caso, el consulado canario y sus asambleas dieron a la fiesta el mismo significado que dio Cádiz a las suyas, mostrar a la casa real francesa sus lazos de adhesión y vasallaje fuera de todo vínculo político con la corona española.

\subsection{Murcia}

Los habitantes de los diferentes estamentos de Murcia también se sumaron a las fiestas por el natalicio del duque de Borgoña. La zona de levante era muy activa comercialmente en los circuitos mediterráneos. Los franceses representaban el grupo mercantil más importante con casas de comercio muy activas en Alicante (Seguí Romá, 2012) y Cartagena tras la guerra de Sucesión (Montojo Montojo, 2010, pp. 216-219). Murcia no quedaba atrás en la primacía del comercio galo pues según 
Guy Lemeunier y María Teresa Pérez Picazo, la segunda mitad del siglo XVIII fue la época dorada de los franceses en la zona, y también en diversas localidades como Caravaca, Lorca o Moratalla (1990, p. 123). La colonia francesa en Murcia arroja según las cifras de Lemeunier y Picazo el número de 131 franceses en 1764 de un total de 238 extranjeros. Un aspecto a destacar de la colonia francesa en la ciudad del Segura es que no contó jamás con un consulado como Cádiz o Tenerife. Alicante y Cartagena gozaron de este, pero en períodos intermitentes (Montojo Montojo, 2010, p. 210). Es por ello que las fiestas en honor del duque de Borgoña no recayeron en una institución de este tipo, sino que los festejos fueron realizados por orden del conde de Vaulgrenant ${ }^{19}$. El panegírico, confeccionado para ser leído en Te Deum, se encargó a Joseph Tomás Blanco (1751) y se dedicó como no podía ser menos al promotor, el diplomático francés. El hecho de ser una fiesta bajo el patrocinio del diplomático y fuera de las pretensiones de un consulado indicaba que el contenido político dado al acontecimiento estaría marcado por el galo y en consonancia con la fiesta que él mismo ofreció en Madrid. La colonia francesa eligió como comisarios de festejos a Juan Francisco Boussac, a quien nos referiremos más adelante, y a Joseph Robí.

\subsubsection{Descripción de las celebraciónes}

La celebración se extendió durante dos días. En la tarde del 13 de noviembre de 1751, la colonia francesa asistió a la iglesia del convento de San Francisco ${ }^{20}$. En la capilla mayor se entonaron las vísperas por la comunidad de religiosos. Se dispusieron fuegos de artificio y se tocaron campanas. El crucero central de la iglesia se adornó con primor enorme y sofisticación. Se levantó una decoración efímera impactante. Se trataba de un altar de tres cuerpos y cuatro órdenes de gradas lujosamente alhajadas. En medio de las gradas en un pabellón se hallaba la imagen de San Luis. Encima de él un arco tallado de cristales, a sus lados otros dos arcos menores acogían las imágenes de San Francisco y San Luis de Tolosa. El cuerpo medio albergaba, siendo la zona más alta, el santísimo sacramento que se hallaba protegido por dos ángeles esculpidos que portaban flores de lis y que mediante un mecanismo lo dejaban cubierto o descubierto. El cuerpo colateral de la derecha tenía un arco de flores artificiales y cornucopias. El colateral izquierdo presentaba las insignias de Santa Isabel de Portugal y Hungría. Toda la obra se iluminó profusamente y estaba guarnecida en damascos y terciopelos carmesíes. Por la noche se tiraron fuegos artificiales y hubo de nuevo repique de campanas. El día 14 se cantó

19 «El comercio de la nación francesa [...] en la intimacion publica, executoriada con el superior orden de V. Excia para que contribuyesen todo los Nacionales a dar las debidas gracias [...] por el feliz nacimiento del Gran Duque de Borgoña» (Blanco, 1751, s.f).

${ }^{20}$ El edificio no existe en la actualidad. 
acción de gracias a San Luis y se expuso el pendón de la orden Trinitaria, a la que pertenecía el rey francés. Después, el padre Blanco pronunció el sermón ante todos los fieles. Terminado este, entró el grueso de la colonia francesa a la iglesia y se cantó el Te Deum. Por la tarde, entre música, se descubrió y luego se volvió a cubrir el Santísimo Sacramento (Blanco, 1751, s. f.).

\subsubsection{El panegírico}

El discurso del panegírico murciano comienza presentando los orígenes «bíblicos» de las monarquías europeas. Las doce tribus de Israel, que tenían su origen en Jacob, quedaron reducidas a cuatro al salir de Egipto. Eran las tribus de Ruben (Francia), Judá (España), Dan (Gran Bretaña), y Ephrain (Alemania). Cada una portaba una bandera: Rubén, la flor de lis (emblema de la Casa de Borbón): Judá, el león (emblema de Castilla): Dan, la rosa (emblema de la Casa Tudor y sucesores); y Ephrain, el águila (emblema del Sacro Imperio). Al bendecir a sus hijos, Jacob concedió al primogénito, Rubén (Francia), la fortaleza, y a Judá (España), la valentía. Al ostentar Rubén la primogenitura, se indicaba que a Francia se le daba la categoría de primer reino. "Estas dos tribus [Rubén y Judá], siempre con la mayor alianza se sucedían el honor al reyno y primogenitura» (Blanco, 1752, pp. 12-13). Esta afirmación evidenciaba que la rama mayor de la familia, Rubén (Francia), debía estar siempre en consonancia con la rama menor (España). En efecto, el monarca galo siempre se consideró y fue considerado por las ramas menores como el cabeza de todas las casas de los Borbones, a las cuales debía proteger ${ }^{21}$. Esta alianza natural se contrapone a la alianza entre los otros hermanos, Ephrain (El Imperio) y Dan (Gran Bretaña). De estos se dice:

Enramados de funesto Cypres, la Rosa con las vanderas de Ephrain, el Aguila en los tafetanes de Dan; esta, porque suspenderá el Aguila de Alemania, el vuelo de sus Reales Plumas, viendo tan unidas las Lyses, à las Garras; aquella, porque las hojas de su lozana Rosa, serán, o arrastradas en castigo, por la inobediencia, al Pastòr de la Iglesia Romana; ò esparcidas al viento, por empleo del olvido, viendo unida en esta nueva Lys, la encrespada guadexa del Hispanico Leon. (Blanco, 1751, p. 13).

Gran Bretaña cometía la traición de unirse a la reforma protestante y, por lo tanto, rompía el lazo indisoluble con sus hermanos. A ella se unía, aunque seguía

${ }^{21}$ El rey de Francia siempre fue sentido como la cabeza principal de todas las ramas de la familia Borbón. Ejemplo de ello es la carta que el embajador Ocariz presentó al ministro de exteriores francés durante la Revolución sobre el juicio a Luis XVI en el proceso que decidiría su suerte. El español insistía en que el proceso contra el jefe de la Casa de Borbón no podía ser visto como algo ajeno al rey de España. La carta se cita en: Muriel, 1959, p. 146. Petitfils (2014, p. 468) también insiste en esta tesis. 
siendo católico, el Imperio. Se pone de manifiesto la existencia de los dos bloques diplomáticos que se conformaron en 1702, con motivo del estallido de la guerra de Sucesión española, hasta la reversión de alianzas de 1756. Gran Bretaña y el Imperio y Francia y España. Las casas de Hannover y Habsburgo contra la de Borbón. Así lo sentía Luis XV de Francia cuando escribía a su primo Fernando VI:

Les anglois ont eté de tout temps les ennemis constants et implacables de notre sang et de notre maison.

Y de Austria decía:

La cour de Vienne ne pardonnera jamais a la France d'avoir etablie Philippe V votre auguste pere, sur le throne de l'Espagne ${ }^{22}$.

El nacimiento del duque de Borgoña se tornaba en la mejor ocasión para volver a recuperar el pacto de Familia contra los enemigos que acechaban y para ello se aludía a lo más preciado, a la endogamia, a la Casa y a la sangre, que era la misma no solo entre los contemporáneos, Luis XV y Fernando VI eran primos hermanos por partida doble ${ }^{23}$, sino que todos sus predecesores la compartían y en especial los dos antepasados tocayos de los reyes, San Fernando y San Luis (Blanco, 1752, p. 26). La dinastía estaba siendo amenazada por los enemigos naturales. El panegírico denota que el discurso religioso legitimaba y se subordinaba al discurso político y era usado de forma estratégica para remover la conciencia de España como guardiana del catolicismo. Así las católicas potencias, el rey católico y el rey cristianísimo debían tener un «indisoluble lazo» (Blanco. p. 17) «repetir contra sus enemigos las victorias» (Blanco, p. 11) «porque aún se herirá a los príncipes del Reyno de Moab» (Blanco, p. 16), identificado como Gran Bretaña y el Imperio.

\section{LOS COMERCIANTES Y LA IDENTIDAD FRANCESA}

Los embajadores de Luis XV se encargaron de celebrar su nacimiento a lo largo y ancho de Europa: en los cantones suizos, Génova, Venecia, Roma, Viena, se realizaron unas espectaculares fiestas. Las cortes de familia italianas, Parma y Nápoles se unen al regocijo, pero la corte en la que realmente se cifraban las esperanzas era la de Madrid. En diversas zonas de España se podía movilizar a la poderosa clase mercantil francesa y a través de ella hacer que el suelo hispano sintiera como

22 Cartas de Luis a XV a Fernando VI, En (Gómez Urdáñez, 1999, p. 244).

${ }^{23}$ Los padres de Luis XV y Fernando VI, Luis, duque de Borgoña, y Felipe V eran hermanos, y las madres, María Adelaida y María Luisa Gabriela eran hermanas. 
propio el natalicio. No en vano comerciantes y mercaderes forman un colectivo que en buena medida es también diplomático en tanto en cuanto representan los intereses de su país en suelo extranjero (Lavandeira Hermoso, 2003, p. 487). Entre Vaulgrenant y el otro "mundo diplomático» debía reinar una cordialidad absoluta. Las instrucciones de Versalles indicaban que él y el cónsul de Cádiz debían velar por los intereses comerciales que la corona española se empeñaba en cercenar cada vez más y de lo que se quejaba agriamente la comunidad mercantil (Hermann, 2004, pp. 27-40). Las colonias comerciales tenían que sobrevivir en un mercado hostil pero atractivo como era el de la Monarquía Hispánica. A pesar, como se comentaba anteriormente, de poder obtener el estatuto de avecindado, muy pocos comerciantes franceses lo solicitaron y en su lugar recurrieron a otras estrategias como el contrabando, aquella "codicia» a la que Luis XV se refería en sus instrucciones al embajador (Morel Fatio, 1899, p. 299) y que provocaban la mano dura de las autoridades españolas. Cabe hacerse una pregunta ¿Por qué los franceses no pedían cartas de naturalización cuando los beneficios eran más que evidentes? La respuesta pasa porque se sentían afectos a la identidad nacional francesa. A pesar de las reticencias que la historiografía muestra a la aplicación del concepto de nacionalismo para el estudio del Antiguo Régimen, "el sentimiento de pertenencia a un estado distinto, por su cultura, sus costumbres y su ideología, estaba ampliamente difundido entre los negociantes franceses» (Bartolomei, 2011, p. 142). Este asunto no es baladí pues se denota en los miembros pertenecientes a los consulados franceses que han sido mencionados en este estudio, los cuales estuvieron relacionados con las fiestas dadas en honor al duque de Borgoña. Tal caso es el de la familia Porlier. Juan Antonio, hijo de Esteban y destinado a sucederle en el consulado canario, no pudo desempeñar el cargo porque al haber nacido en Tenerife era súbdito del rey de España y no del de Francia. Juan Antonio protestó alegando que su madre era francesa y que había nacido en la casa del consulado francés. Por otro lado, su padre los había enviado a estudiar a Francia en vez de a España porque quería que conservaran su «corazón francés» (Ozanam, 2002, pp. 2181-2182). El mismo caso sucedía con Juan Francisco Boussac, nacido en Alicante, era hijo de un comerciante francés. Sin embargo, su lugar de nacimiento no era óbice para que se sintiera plenamente francés, pues en el panegírico murciano no dudaba en presentarse como súbdito de Luis XV. Además, en 1770 contrajo matrimonio con María Ángela Bordenabe, hija de un mercader francés ${ }^{24}$.

En ocasiones cabía dudar de la sinceridad de los comerciantes franceses, pues a veces el oportunismo se imponía. A pesar de solicitar la carta de naturalización, estos podían hacerse pasar por naturales o por transeúntes a su conveniencia,

24 Ozanam, D. Juan Francisco Boussac. Diccionario biográfico de la Real Academia de la Historia. Recuperado el 07 de febrero de 2021 de https://dbe.rah.es/biografias/51486/juanfrancisco-boussac 
lo que explica el ansia de la corona española por realizar las listas de extranjeros (1764-1791) para distinguir entre unos y otros y evitar fraude. Aunque exteriormente pudieran aparentar que el deseo de naturalización era sincero, realmente podían abrigar el proyecto de regresar al país natal después de haber hecho fortuna. (Bartolomei, 2011, p. 135). Los comerciantes franceses de Cádiz eran el ejemplo de ello, pues consideraban a la ciudad como el lugar de iniciación en los negocios de los miembros más jóvenes de las familias mercantiles. Cuando pasado un tiempo estos habían hecho riqueza y habían adquirido experiencia, volvían a Francia y dejaban su puesto en la ciudad gaditana a otro miembro de la familia para repetir el proceso (García-Baquero González, Collado Villalta, 1990, pp. 188-189). Boussac es un caso paradigmático de tránsfuga «nacional», pues pasó de mostrarse como leal súbdito francés en 1751, a ejercer el puesto de cónsul de España en Sète (Francia), para lo cual era necesario ser naturalizado español. No tardó en volver a dar un salto en su identidad cuando en 1790 en esta ciudad francesa pronunció un discurso público que mostraba sus simpatías con los cambios revolucionarios (Ozanam, 1998, p. 197). Boussac puede clasificarse dentro de la gran variedad de situaciones intermedias que indicaban que uno podía ser a veces más extranjero que natural o más natural que extranjero (Herzog, 2011, p. 27). Sería este primer criterio, el sentirse más francés que español, el que mejor lo definiría cuando se presentó como defensor de la revolución, lo cual provocó su arresto por orden de Floridablanca. Posteriormente fue liberado, pero sospechoso de tener contactos revolucionarios fue encarcelado de nuevo (Ozanam, 1998, p. 197). Sin embargo, fue este mismo criterio el que permitió a Boussac presentarse cuarenta años antes como un leal súbdito de la corona francesa y deleitado por el nacimiento de un duque de Borgoña.

Quedaba claro pues que la conciencia de pertenencia se imponía a la naturalización. No obstante, los franceses querían aprovecharse a toda costa de la riqueza del comercio español y por ello mostraban su fidelidad y celo con el rey de Francia y con su familia, porque este y sus ministros eran los que podían abrirles las puertas del mercado colonial español (Christelow, 1941). Los franceses eran conscientes de que pertenecían al por entonces reino más reputado de Europa, al que todos trataban de emular y cuya cultura era objeto de deseo y esto les enorgullecía (Fumaroli, 2015).

\section{CONCLUSIONES}

A pesar de la disparidad de criterios adoptados en las celebraciones, unas exaltando a la casa real francesa en España y otras introduciendo los elementos dinásticos que la unía a la de España, las fiestas en honor al duque de Borgoña consiguieron un objetivo común, y fue el de frenar la galofobia que ministros como Carvajal se encargaban de alimentar en el pueblo (Gómez Urdáñez, 1999, p. 220). En el 
Antiguo Régimen la fuerte estratificación social hacía que cada estamento ocupara un lugar determinado en las celebraciones festivas, las fuentes, tanto los panegíricos como la relación de la fiesta dada en Madrid, apuntan a que todos los grupos sociales participaron del festejo. Si bien los nobles lo hacían como protagonistas, siendo los actores que presidían los banquetes, los bailes, los refrescos y las mascaradas, el pueblo llano también ejercía su representación e intervenía, dentro de la esfera que se le asignaba, en lo festivo. En Madrid, como hemos señalado antes, todos quedaron encantados con las fiestas incluidos los reyes. La nobleza disfrutó de la cena, el refresco y los bailes dados por el embajador mientras que el pueblo se deleitó con los fuegos de artificio. En Cádiz las autoridades y los miembros del consulado disfrutaron de la cena y refresco en la casa del embajador, mientras que gentíos acudieron a contemplar las iluminaciones en la plaza de San Antonio. En Murcia todos los estados (autoridades y estado llano) se reunieron en el convento de San Francisco para escuchar el panegírico, moviendo a la iglesia tanto al "sabio» como al «rústico» (Blanco, 1751, s. f.). En Canarias el concurso de nobles (autoridades locales), que asistieron al Te Deum, y plebeyos, que asistieron a contemplar la procesión de la hostia consagrada y a disfrutar de la música y las luminarias, tampoco faltó (Medina, 1752, s. f.). La consensuada elección de las capillas de San Luis en los conventos de San Francisco, la exaltación de este como rey cruzado como defensor del catolicismo, el hincapié puesto en propugnar que era predecesor tanto del rey católico como del rey cristianísimo, y la sublimación del nuevo príncipe real, el duque de Borgoña, elenco de virtudes y pariente de sangre de Fernando VI, pretendía hacer ver que Francia era la amiga natural de España porque su Casa Real era ardiente defensora del catolicismo, como lo era el rey de España, y porque poseía una lista interminable de virtudes. Se pretendía claramente, por medio del artificio de la fiesta, crear una corriente de opinión favorable a Francia entre el pueblo y las autoridades pues todos fueron partícipes y receptores de los mensajes transmitidos en las festividades. Estas celebraciones debieron de ser un fuerte revés para Carvajal, pues el ministro evitaba por todos los medios cualquier acto que pudiera significar una unión entre España y Francia, y estas fiestas pretendían tener precisamente ese propósito ${ }^{25}$.

Pero todo quedó en nada, pues Fernando VI no cambió un ápice de su política. La sustitución de Puyzieulx por el marqués de Saint Contest en el ministerio de exteriores marcó el fin de Vaulgrenant como embajador. La influencia del mariscal de

${ }^{25}$ La concesión del Toisón de oro al pequeño duque de Borgoña por presiones del duque de Duras, sucesor de Vaulgrenant, eran el tipo de actos que detestaba Carvajal. Cuando por iniciativa también de Duras, Luis XV envío cordones del Saint Esprit para que Fernando VI los repartiera, el ministro español escribió a Masones de Lima, embajador en Versalles, de que intentase frenar este asunto. Ozanam, (2006). En su testamento político, Carvajal escribía sobre los franceses: «[...] tienen para nosotros una enemistad irreconciliable, que nos asesinarán hasta el último exterminio siempre que puedan [...]» (Carvajal y Lancaster, 1745, p. 8-r-v). 
Noailles sobre el nuevo ministro era total y en opinión de este, Vaulgrenant llevaba en Madrid una vida retirada y sin lustre que desacreditaba su calidad de embajador en Francia (Ozanam, 2006). El diplomático había fracasado en reforzar oficialmente la alianza hispano francesa (Gómez Urdáñez, 1999, p. 219). Fue notificado de su cese el 25 de abril de 1752 y llegó a Versalles el 13 de noviembre ${ }^{26}$. En su lugar fue nombrado el duque de Duras, que tenía como fin en la corte española la misma misión que su antecesor, recuperar la amistad española. Sin embargo, este, queriendo corregir todo lo que se reprochaba a Vaulgrenant (Gómez Urdáñez, 1999, p. 221), actuó si cabe de manera más temeraria y finalmente tuvo que ser cesado.

Todo auguraba al duque de Borgoña una vida gloriosa, primero como príncipe y luego como rey. Sin embargo, su vida se vio truncada con apenas diez años el 22 de marzo de 1761 tras la caída de un caballo. Todas las virtudes con que se le adornaron en sus panegíricos de nacimiento fueron volcadas en los de defunción, donde se le fabricó una vida santa, estrategia política ante los graves problemas que afrontaba la monarquía francesa en el siglo XVIII (Hours, 2006). Su muerte, al igual que su vida, fue instrumentalizada políticamente.

\section{REFERENCIAS BIBLIOGRÁFICAS}

\subsection{Impresos}

Almanach pour l'année bissextil M. DCC L II. París: chez Charpentier, rue S.t Jacques au Coq. BNF: FRBNF41507546.

Blanco, J. T. (1751). Oracion encomiastica y gratulatoria : que en los solemnes cultos, que executó el comercio de la nación francesa de esta ciudad de Murcia, al glorioso San Luis Rey de Francia ... por la real sucessión del ... Señor Delfin en el ... nacimiento del real infante Duque de Borgoña en el día 14 de noviembre de ... 1751 / dixo ... Fr. Joseph Thomas Blanco ... de la Regular Observancia de N. P. S. Francisco ... ; sacala a luz el comercio de dicha nación ... Murcia: Imprenta de Nicolás loseph Villargordo y Alcaráz. Biblioteca de la provincia franciscana de Cartagena: 0100(2).

Blanco, J. T. (1704). Le triomphe de la Seine et du Tage, Sur les autres fleuves de I'Europe, affermi par la naissance de Monseigneur le duc de Bretagne. París: Imprenta de Jean L'Esclapart. BNF: FRBNF36298031.

${ }^{26}$ Carta de Jaime Masones de Lima a Carvajal, París, 13 de noviembre de 1752. En (Ozanam, 2001, p. 50). 
Blanco, J. T. (1751). Mandement... qui ordonne que le Te Deum sera chanté... en actions de grâces de l'heureux accouchement de madame la dauphine et de la naissance d'un duc de Bourgogne. París: Imprenta C. Simon. BNF: FRBNF33791097.

Medina, B. (1752). El parabien de la Europa por la nueva lis de Francia : sermon panegirico que en la solemne accion de gracias celebrada por la feliz noticia de el nacimiento del Serenisimo Señor Innfante Duque de Borgoña / predicò ... Blas de Medina ... el dia 23 de Abril año de 1752 sacalo a luz publica D. Enrique Cassalon. Santa Cruz de Tenerife: Imprenta Real de Guerra.

Mercure de France. (1751, julio-diciembre). Tomo LXI.

Monsieur Soret (1751). Ode sur la naissance de Monseigneur le duc de Bourgogne, présentée à Mgr le Dauphin, par M. Soret,... París: Imprenta de B. Brunet. BNF: FRBNF31385817.

Rameau, J. P. (1751). Achante et Céphise. París: chez l'auteur, rue de Richelieu, visà-vis la bibliothèque du Roi : la Veuve Boivin, marchande, rue Saint Honoré, à la Régle d'Or: M. Leclerc, marchand, rue du Roule, à la Croix d'or. BNF: FRBNF41416888.

Rameau, J. P. (1751). Représentation du feu d'artifice tiré le 3 Octobre 1751 sur la rivière d'Ill... à l'occasion de la naissance de Monseigneur le Duc de Bourgogne. S.I; S.L. BNF: FRBNF41925337.

\subsection{Estudios}

Albareda Salvadó, J. (2010). La guerra de Sucesión de España. Barcelona: Crítica.

Bartolomei, A. (2011). La naturalización de los comerciantes franceses de Cádiz a finales del siglo XVIII y principios del XIX. Cuadernos de Historia Moderna, Anejos, 10, pp. 123-144. https://doi.org/10.5209/rev_CHMO.2011.38673

Bartolomei, A. (2017). Les marchands français de Cadix et la crise de la «Carrera de Indias» (1778-1828). Madrid: Casa de Velázquez.

Baudrillart, A. (1890-1901). Philippe V et la cour de France, 5 vols. París: Libraire de Firmin-Didot et Cie. 
Bennassar, B. (2004). Sur un thème cher à Didier Ozanam, Les étrangers en Espagne à l'époque moderne. En J. P. Dedieu y B. Vincent (eds.), L'Espagne, l'État, les lumières, Mélanges en l'honneur de Didier Ozanam (pp. 17-26). Madrid: Collection de la Casa de Velázquez, Maison de Pays Ibériques.

Bernardo Ares, J. M., Echevarría Pereda, E., Ortega Arjonilla, E. (2011). De Madrid a Versalles, la correspondencia bilingüe entre el rey sol y Felipe $V$ durante la guerra de Sucesión. Barcelona: Ariel.

Bottineau, Y. (1986). L'Art de cour dans l'Espagne des Lumières, 1746-1808. París: De Boccard.

Bustos Rodríguez, M. (1995). Los comerciantes de la carrera de Indias en el Cádiz del siglo XVIII (1713-1775). Cádiz: Universidad de Cádiz: Servicio de Publicaciones.

Bustos Rodríguez, M. (2016). La toile de fond du consulat français àCadix : la ville et ses opportunités au XVIII ${ }^{e}$ siècle. En A. Mézin y A. Pérotin-Dumon (dirs.), Le consulat deFrance à Cadix: Institution, intérêts et enjeux (1666-1740). Pierrefitte-sur-Seine: Publications des Archives nationales. https://doi. org/10.4000/books.pan.414.

Chaline, O. (2009). L'année des quatre dauphins. París: Flammarion.

Christelow, A. (1941). French interest in the Spanish empire during the ministry of the duc of Choiseul, 1759-1771. The Hispanic American Historical Review, 4, pp. 515-537. https://doi.org/10.1215/00182168-21.4.515

Delgado Barroso, J. M. (2001). El proyecto político de Carvajal. Pensamiento y reforma en tiempos de Fernando VI. Madrid: CSIC.

Delorme, P. (2020). Fetes et cérémonies à Versailles. Chateau de Versailles, de l'Ancien Régime à nos jours, HSO6.

Fumaroli, M. (2015). Cuando Europa hablaba francés, extranjeros francófilos en el siglo de las luces. Barcelona: Acantilado.

Gómez Urdáñez, J. L. (1999). El duque de Duras y el fin del ministerio Ensenada (17521754). Hispania, 201, pp. 217-249. https://doi.org/10.3989/hispania.1999.v59. i201.623 
Gorce, De la, J. M. (2007). Le Triomphe de la Seine et du Tage sur les autres Fleuves de l'Europe, affermi par la naissance du duc de Bretagne. Une fête organisée à Paris pendant la guerre de Succession d'Espagne. En A. Álvarez Ossorio Alvariño., B. J. García García y V. León Sanz (coords.), La pérdida de Europa, la guerra de Sucesión por la Monarquía de España (pp. 49-64). Madrid: Fundación Carlos de Amberes.

Gouic. Le, O. (2013). Les négociants dans les assemblées de la Nation française à Cadix : représentation, assiduité et implication du négoce dans les affaires du Consulat de France (1716-1728). Annales de Bretagne et des Pays de l'Ouest, 120(1), pp. 97-127. https://doi.org/10.4000/abpo.2567

García-Baquero González, A y Collado Villalta, P. (1990). Les français à Cadix au XVIII siècle: La colonie marchande. En J. P. Amalric y G. Chastagnaret (eds.), Les français en Espagne à l'époque moderne (XVI -XVIII siècles (173-196). París: Éditions du centre national de la recherche scientifique.

Herzog, T. (2011). Naturales y extranjeros sobre la construcción de categorías en el mundo hispánico. Cuadernos de Historia Moderna, Anejos, 10, pp. 21-31. https://doi.org/10.5209/rev_CHMO.2011.38668

Hours, B. (2006). La mort du petit prince: le duc de Bourgogne (1761). En O. Christin y B. Hours (dir.), Enfance, assistance et religion (pp. 69-79). Larhra. https://doi. org/10.4000/books.larhra.1176

Igual Castelló, C. (2019). «Con dos infantes colma la real cuna». The festivals for twin grandchildren of Charles III and for the British peace in 1784. En O. Rojewski y M. Sobezynska-Szczepanska (eds.), Court, nobles and festivals: Studies on the Early Modern visual culture (pp. 125-140). Katowice: University of Silesia Press.

Kamen, H. (2000). Felipe V, el rey que reinó dos veces. Barcelona: Temas de hoy.

Lavandeira Hermoso, J. C. (2003). Diplomáticos europeos en la España de mediados del siglo XVIII. Inmigrantes de ida y vuelta. En M. B. Villar García y P. Pezzi Cristóbal (eds.), Los extranjeros en la España Moderna, tomo II (pp. 485-493). Málaga: Ministerio de Ciencia e Innovación.

López Cordón, M. V. (2000). Pacte de Famille ou interets d'Etat? La monarchie française et la diplomatie espagnole du XVIIle siècle. En Bely, L. (dir.), La présence des Bourbons en Europe XVIe-XXIe, siècle (pp. 185-205). París: Presses Universitaires de France. 
Lemeunier, G y Pérez Picazo, M. T. (1990). Les français en Murcie sous l'Ancien Régimen (v. 1700-v. 1850) Des migrations populares au grand commerce. En J. P. Amalric y G. Chastagnaret (eds.), Les français en Espagne à l'époque moderne (XVIe-XVIII siècles (pp. 111-138). París: Éditions du centre national de la recherche scientifique.

Molina Martínez, J. M. (2004). De propios y extraños. La población de Cádiz en el siglo XVIII. Cádiz: Universidad de Cádiz: Servicio de Publicaciones.

Montojo Montojo, V. (2010). El comercio de Cartagena y Alicante tras la guerra de Sucesión. Espacio, Tiempo y Forma, Serie IV, Historia Moderna, 23, pp. 203226. https://doi.org/10.5944/etfiv.23.2010.1627

Morel Fatio, A. (1899). Recueil des instructions données aux ambassadeurs et ministers de France depuis les traitres de Westphalie jusqu' a la revolution française. Tome 12bis, Espagne.

Muriel, A. (1959). Historia de Carlos IV. Edición de Carlos Seco Serrano, Biblioteca de Autores Españoles.

Mínguez, V y Rodríguez Moya, I. (2020). El tiempo de los Habsburgo, la construcción artística de un linaje imperial en el Renacimiento. Madrid: Marcial Pons.

Ozanam, D. Juan Francisco Boussac. Diccionario biográfico de la Real Academia de la Historia. Recuperado el 07 de febrero de 2021 de https://dbe.rah.es/ biografias/51486/juan-francisco-boussac

Ozanam, D. (1968). La colonie française de Cadix au XVIIIe siècle d'après un document inédit (1777). Mélanges de la Casa de Velázquez, 4, pp. 259-348. https://doi.org/10.3406/casa.1968.981

Ozanam, D. (1998). Les diplomates espagnols du XVIIle siècle. Madrid: Casa de Velázquez, Maison de Pays Ibériques.

Ozanam, D. (2000). Fiestas diplomáticas francesas en España (1751-1752). En M. Torrione (dir.), España festejante, el siglo XVIII (pp. 231-238). Málaga: Diputación de Málaga, Cedma.

Ozanam, D. (2000). Dinastía, diplomacia y política exterior. En P. Fernández Albaladejo (coord.), Los Borbones, dinastía y memoria de nación en la España del siglo XVIII (pp. 17-46) Madrid: Marcial Pons, Casa de Velázquez. 
Ozanam, D. (2000). El consulado francés en Canarias y la familia Porlier. En XIV Coloquio de historia Canario-Americana, pp. 2173-2185.

Ozanam, D. (ed.). (2001). Un español en la corte de Luis XV, cartas confidenciales del embajador Jaime Masones de Lima, 1752-1754. Alicante: Servicio de Publicaciones de la Universidad de Alicante.

Ozanam, D. (2006). La Crisis de las Relaciones Hispano-Francesas a mediados del Siglo XVIII. La Embajada de Jaime Masones de Lima (1752-1761). Tiempos Modernos, 5(14). http://www.tiemposmodernos.org/tm3/index.php/tm/ article/view/101/134

Petitfils, J. C. (2014). Louis XV. París: Perrin. https://doi.org/10.3917/perri. petit.2018.01

Sage, H. (1903). Les ambitions de Louise-Élisabeth de France, duchesse de Parme, ses intrigues a la cour de Versailles, Revue de Sciences Politiques, 18, pp. 686701.

Salas Ausens, J. A. (1990). Les français en Espagne dans la seconde moitié du XVIII siècle. En J. P. Amalric y G. Chastagnaret (eds.), Les français en Espagne à l'époque moderne (XVle-XVIII siècles (pp. 155-171). París: Éditions du centre national de la recherche scientifique.

Sancho Gaspar, J. L. Francisco Antonio Carlier. Diccionario Biográfico de la Real Academia de la Historia. Recuperado el 7 de febrero de 2021 de https://dbe. rah.es/biografias/17382/francisco-antonio-carlier

Seguí Romá, V. (2012). Comerciantes extranjeros en Alicante (1700-1750). Hombres de negocios franceses y genoveses en una ciudad mediterránea. Alicante: Universidad de Alicante.

Stryiensky, C. (1902). La mère des trois dernieres Bourbons: Marie-Josèph de Saxe et la cour de Louis XV. París: Plon. 
